\title{
Ductal carcinomas in situ and invasive cancers detected on screening mammography: Cost-effectiveness of initial and subsequent rounds of population-based program 2007-2014
}

\author{
Bartłomiej Szynglarewicz ${ }^{1,2, A-D}$, Rafał Matkowski, 2, A, E, F \\ ${ }^{1}$ Department of Surgical Oncology, and Regional Coordinating Center for Screening Programs, Lower Silesia Oncology Center - Regional Comprehensive Cancer Center, \\ Wrocław, Poland \\ ${ }^{2}$ Department of Oncology, Wroclaw Medical University, Poland \\ A - research concept and design; $\mathrm{B}$ - collection and/or assembly of data; $\mathrm{C}$ - data analysis and interpretation; \\ $\mathrm{D}$ - writing the article; $\mathrm{E}$ - critical revision of the article; $\mathrm{F}$ - final approval of article
}

Address for correspondence

Barttomiej Szynglarewicz

E-mail: szynglarewicz.b@dco.com.pl

Funding sources

none declared

Conflict of interest

none declared

Acknowledgements

Authors thank Dawid Błaszzzyk (Regional Coordinating Center for Screening Programs, Wroctaw, Poland) for his kind and careful assistance in data collection and analysis.

Received on August 20, 2015

Revised on September 03, 2015

Accepted on February 18, 2016

\begin{abstract}
Background. Potential benefits of screening need to be carefully balanced against the financial burden for the national health care system.

Objectives. To assess the cost-effectiveness of population-based mammographic screening in the 3-million region of Lower Silesia (Poland) after initial and 3 subsequent rounds.

Material and methods. Data was collected in a prospective manner using the databases of the official computer system for the monitoring of prophylaxis programs (SIMP), National Health Fund (Lower Silesia Regional Branch) and the Lower Silesia (ancer Registry. The expenses from each analyzed year were obtained from the Regional Coordinating Center for Screening Programs. The number of screen-detected and pathologically proven invasive and ductal in situ cancers was calculated. Costs of cancer detection were measured, converted into US dollars (USD), and expressed in 2015 USD using the comparison of purchasing power of money calculated with the Consumer Price Index.
\end{abstract}

Results. The total expense for the screening program in the initial round (2007-2008), first (2009-2010), second (2011-2012) and third (2013-2014) subsequent rounds was 4732 383, 6043 509, 6484 834, and 5900793 USD whereas the number of cancer detected was 1049, 987, 1312, and 1070. The costeffectiveness ratio obtained in the program for each year was 4511, 6123, 4943, and 5515 USD per cancer found. The average cost of breast cancer detection in screening program in the region of Lower Silesia in years 2007-2014 was 5243 USD.

Conclusions. The low cost of breast cancer detection in mammographic screening program makes it applicable for the health care systems in emerging economies.

Key words: breast cancer, mammographic screening, cost-effectiveness

DOI

10.17219/acem/61841

Copyright

Copyright by Author(s)

This is an article distributed under the terms of the

Creative Commons Attribution Non-Commercial License

(http://creativecommons.org/licenses/by-nc-nd/4.0/) 


\section{Introduction}

Despite important advances in therapy and translational research, strategies for breast cancer control are geared towards early detection of the disease. ${ }^{1-3}$ In high-income economies, such as US or Western European Countries, mammographic screening has been widely implemented, leading to various improvements in breast cancer treatment outcomes. ${ }^{3-6}$ However, cost-effectiveness of organized and centralized screening has to be taken into account when a nation-wide program is introduced, in particular in emerging countries. Although Poland is ranked by the World Bank as belonging to high-income countries (http://data.worldbank.org/country), the gross national income (GNI) per capita (13 730 USD) remains considerably lower than in Western Europe, and is just slightly above the borderline value (12 616 USD), which results in strongly limited health care budget. There is mixed data regarding the economic attractiveness of mammographic screening in low- and middle-income countries. The evidence base is still too small to generalize these findings and draw significant conclusions. ${ }^{3}$

Lower Silesia is a region with 3 million inhabitants in southwest Poland. Since the introduction of mammographic screening, approximately 60000 women have been screened each year. During the initial (2007-2008) and first subsequent (2009-2010) round of screening the technical recall rate was $0.27 \%$ and $0.1 \%$, whereas further assessment rate $6.2 \%$ and $4.5 \%$, respectively. The cancer detection rate (both invasive and ductal in situ) was 6.6/1000 and 5.5/1000 while cancer detection rate, expressed as a multiple of the expected breast cancer incidence rate, was 3.8 and 3.3 , respectively. ${ }^{7}$ Positive predictive value of screening test and the further assessment was 11 and 77\%, respectively. ${ }^{7,8}$ The general assessment using early indicators reveals that diagnostic service conforms to the European standards on an acceptable or even desirable level. ${ }^{9}$ Because these operational objectives are accomplished, the program has a chance to replicate a significant reduction in breast cancer mortality achieved in randomized trials. On the other hand, the potential benefits of screening need to be carefully balanced against the financial burden for the national health care system. ${ }^{10}$ However, except for our preliminary report from the first year of screening, no other complex analysis of breast cancer detection costs has been done yet. ${ }^{11}$

The aim of this study was to evaluate the cost-effectiveness of population-based mammographic screening in the region of Lower Silesia.

\section{Material and methods}

Population-based breast cancer screening in Poland has been fully introduced on January 1, 2007 (after a pilot phase in 2006) by the Polish National Health Fund. This nation-wide program targets women aged 50-69 that are not undergoing treatment or being followed-up due to breast cancer. Personal invitation letters are issued centrally by the National Health Fund based on its population register. Two-view screen-film mammography, craniocaudal and oblique, is used as a standard screening test. Routine round length of the program is 2 years. All women with radiological findings categorized as BIRADS 3-5 are recalled for assessment. The second level diagnostic tools are breast clinical examination, additional imaging, and invasive investigations if needed. Following further assessment women are referred to the mammography at the routine round length of the program (benign lesions), to the short-term follow-up after 6 months (lesions of uncertain potential of malignancy), or to the treatment if breast cancer had been detected on biopsy (core-needle or vacuum-assisted).

Data was collected in a prospective manner using SIMP computer system (the official electronic system for monitoring of prophylaxis programs), as well as the databases of the regional branch of National Health Fund and the Lower Silesian Cancer Registry. The amount of expenses during the each analyzed year was obtained from the Regional Coordinating Center for Screening Programs. The number of screen-detected cancers comprises both ductal carcinomas in situ and invasive breast cancers. Costs of invasive investigations are included into the costs of the further assessment with the exception of vacuum-assisted biopsy that is reimbursed separately. Costs were measured, converted into US dollars (USD), and expressed in 2015 USD using the comparison of purchasing power of money calculated with the Consumer Price Index (CPI). Calculations were done using the database of Polish National Bank (www.nbp.pl) to determine exchange rates and the Measuring Worth service to measure the worth of amounts in USD over the time (www.measuringworth.com).

\section{Results}

The expense for screening mammograms in the initial round (2007-2008), first (2009-2010), second (20112012) and third (2013-2014) subsequent rounds was 4 051 666, 5453 418, 5767 905, and 5244519 USD, while the cost of invitation letters was $135667,144320,188130$, and 144 886, respectively. Expenses connected to further assessment were 207 167, 208 739, 183 991, and 163615 USD. Operating costs related to the activity of the Regional Coordinating Center for Screening Programs included screening promotion, advertising campaigns, courses for health professionals, as well as the maintenance of information phone-line and website, data collection and analysis. These costs amounted to 337 883, 237 032, 344 808, and 347773 USD. To sum up, the total expense for the screening program was 4732 383, 6043 509, 6 484 834, and 5900793 USD, whereas the number of cancer detect- 
Table 1. Detailed cost of breast cancer screening in the region of Lower Silesia in the years 2007-2014 expressed in 2015 USD

\begin{tabular}{|c|c|c|c|c|c|c|c|c|}
\hline Expenses & 2007 & 2008 & 2009 & 2010 & 2011 & 2012 & 2013 & 2014 \\
\hline Screening mammograms & 1851666 & 2200000 & 2566667 & 2886751 & 3007820 & 2760085 & 2701437 & 2543082 \\
\hline Recall and further assessment & 82500 & 124667 & 110000 & 98739 & 99779 & 84212 & 88671 & 74944 \\
\hline Invitation letters & 99000 & 36667 & 38500 & 105820 & 93185 & 94945 & 90491 & 54395 \\
\hline Regional coordinating center & 156383 & 181500 & 119167 & 117865 & 183395 & 161413 & 192465 & 155308 \\
\hline Total expense & 2189549 & 2542834 & 2834334 & 3209175 & 3384179 & 3100655 & 3073064 & 2827729 \\
\hline Cancers detected ${ }^{1}$ & 543 & 506 & 463 & 524 & 666 & 646 & 537 & 533 \\
\hline Expense per cancer detected & 4032 & 5025 & 6122 & 6124 & 5081 & 4800 & 5723 & 5305 \\
\hline
\end{tabular}

1 invasive cancers and ductal carcinomas in situ.

ed was 1 049, 987, 1312 , and 1 070. The cost-effectiveness ratio obtained in the program for each year was 4511 , 6123,4943 , and 5515 USD per cancer found. During the 8 years of program, the expense for screening mammograms and further assessment was 20517508 and 763 512, respectively, while the cost of invitation letters and the operating cost of the Regional Coordinating Center was 613003 and 1267 496, respectively. The total expense for screening program and the number of detected cancers was 23161519 and 4 418, respectively. The average cost of breast cancer detection in screening program in the region of Lower Silesia in years 2007-2014 was 5243 USD. The year-by-year analysis is presented in details in Table 1.

\section{Discussion}

To compare the costs and effects among different screening programs is difficult. Cost-effectiveness of mammographic screening generally favors the organized and centralized programs, mainly because of better organization, attendance rate, extended invitation scheme covering a large part of the eligible population and comprehensive quality assurance procedures. ${ }^{10}$ Published cost-effectiveness ratios may differ tremendously, but are often the result of different methods of calculation, time periods considered, including or excluding downstream cost. The effects of screening depend on many factors, such as the epidemiology of disease, the health care system, the quality of program, and the costs of health care. ${ }^{12}$ Estimation using a computer model showed that these marked differences make it impossible to set up one uniform policy for all the countries. ${ }^{10,12}$ When we evaluate the cumulative expense for mammographic screening with regard to the number of cancers found, our program looks favorable. If we assess the similar period at the start of program, the reported cost of cancer detection expressed in 2014 USD varied from 11385 (Italy, 19911992) to 12925 (Spain, 1995-1996). ${ }^{13,14}$ Our screening seems to be much more cost-effective but the limitations of that comparison should be kept in mind. This difference is hard to explain. It might have been influenced by many factors, since the number of cancers detected is the product of screening sensitivity, incidence of breast cancer in the eligible population, and the percentage of women screened. ${ }^{15}$ Moreover, lower reimbursement rates and salary levels in the Polish health care system compared to those in Western Europe are among many other possible explanations.

Burnside et al. used a special economic model to simulate mammography and estimate the aggregate cost and quality of screening in the US. The model generates the total USD (2001) spent on screening for the base case assumptions. Assuming approx. 65\% attendance rate, a $4-7.8 \%$ recall rate, and a 30-35\% cancer to biopsy ratio, the total cost would be 4517 billion USD while the number of biopsies performed would be $337000 .{ }^{15}$ Through this model, the costs and cancers detected can be evaluated using different recall and biopsy characteristics. This model shows that approaching the screening goal of maximum participation (100\%) would produce extremely different cost characteristics depending on the practice style parameters. The low recall rate $(2.5-3.5 \%)$ and high cancer to biopsy ratio (47\%) style saves over 697 million USD and over 137000 biopsies as compared with the base case. On the other hand, the high recall rate (11\%) and low cancer to biopsy ratio $(<11 \%)$ style would cost almost 3198 billion USD more than the base case and would generate 1156000 more biopsies. An analysis of the number of women who can be screened and evaluated for a fixed expenditure also reflects the financial impact of distinct practice characteristics. For example, if 4 billion USD is available for breast cancer screening, the program screens (using the base case values) $67.3 \%$ of the population; 87968 cancers will be diagnosed, and 295000 women will undergo biopsy. This program, which uses a low recall rate and high cancer to biopsy ratio screens $75.5 \%$ of the population; 98541 cancers will be detected, and 244000 women will undergo biopsy. The benefit is an additional 10000 breast cancers diagnosed early by mammography with a reduction in over 50000 biopsies. In contrast, a program performed with high recall rate and a low cancer to biopsy ratio would screen only the $50.1 \%$ of the eligible population; 713000 women will 
undergo biopsy, yet only 65911 cancers will be detected. For the same health care USD, an excess of $418000 \mathrm{bi}$ opsies are carried out as compared with the base case. Despite this aggressive style, more than 22057 cancers go undetected by mammography because of the low participation rate. ${ }^{15}$

Theoretic models suggest that the marginal cost per year of life saved by screening can be reduced up to $23 \%$ with substitution of minimal-invasive biopsy for open surgery. ${ }^{16}$ Liberman et al. estimated that stereotactic biopsy could decrease cost of diagnosis by $50 \%$ with annual national reduction in cost approaching 200 billion USD. ${ }^{17}$ Rubin et al. compared the cost-effectiveness of distinct methods of invasive investigation in their analysis of consecutive biopsy procedures for non-palpable mammographic abnormalities performed from 1984 (needle-localized surgery) to 1998 (vacuum-assisted core biopsy). Increased use of minimal-invasive techniques, instead of open biopsies, resulted in a significant decrease in the total expense for cancer detection from 19503 to 14490 USD (1998). ${ }^{18}$ If expressed in 2014 USD, the cost of breast cancer diagnosis is reduced from 28380 to 21010 USD, which gives an important 7370 USD saving per each cancer case.

The studies mentioned above clearly indicate that some performance indicators can reflect the cost-effectiveness of the screening program. Taking this under consideration, our service seems to work well. The recall rate is acceptable (in the base case range), minimal-invasive biopsy rate (core-needle and vacuum-assisted) is on a desirable level (95\%), while the cancer to biopsy ratio is very high (72\%). ${ }^{7,8}$ The main disadvantage of our analysis is the fact that since vacuum-assisted biopsy is reimbursed separately, its cost is not included into a total expense for screening program. For the attendees' convenience, over $90 \%$ of screening mammograms are completed in many small services outside our hospital in strict accordance to high quality standards. However, a vast majority of the vacuum-assisted procedures in the region of Lower Silesia and almost all of these biopsies for screen-detected abnormalities are performed in our institution. Hence, some conclusions can be drawn. The reimbursement rate for vacuum-assisted procedure in Poland between 2007 and 2009 was approximately 1000 USD. This type of biopsy offers considerable advantages, but because of the limited budget it was generally reserved for microcalcifications (under stereotactic guidance) and for very small mass lesions (ultrasound-guided). In 2007 the number of cancers found in the screening program was 543. As we reported elsewhere, in the same year a minimal-invasive biopsy rate was $95 \%$, while a benign to malignant ratio was $1: 2.55$, which gives a cancer to biopsy ratio as high as $72 \% .{ }^{19}$ To confirm a malignant histology of screen-detected lesions, a total number of core-needle and vacuumassisted biopsies performed in that year was 254 and 462 , respectively. If we include the additional cost of vacuumassisted procedures (462 000 USD) into the total expense for screening program the cost of cancer detection will rise up to 4517 USD, which still remains low.

In conclusion, our findings indicate that because of low cancer detection cost a population-based mammographic screening conforming the European quality standards is cost-effective for emerging economies. It should be an important part of the public policy even in countries with strongly limited health budget.

\section{References}

1. Maciejczyk A. New prognostic factors in breast cancer. Adv Clin Exp Med. 2013;22:5-15.

2. Wojnar A, Puła B, Podhorska-Okołów M, Dzięgiel P. Discrepancies between HER2 assessment form core needle biopsies and surgical specimens of invasive ductal breast carcinoma. Adv Clin Exp Med. 2013;22:27-31.

3. Zelle SG, Baltussen RM. Economic analyses of breast cancer control in low- and middle-income countries: A systematic review. Syst Rev. 2013;2:20.

4. Coleman MP, Forman D, Bryant $\mathrm{H}$, et al. Cancer survival in Australia, Canada, Denmark, Norway, Sweden, and the UK, 1995-2007 (the International Cancer Benchmarking Partnership): An analysis of population-based cancer registry data. Lancet. 2011;377:127-138.

5. DeSantis C, Siegel R, Bandi P, Jemal A. Breast cancer statistics 2011. CA Cancer J Clin. 2011;61:409-418.

6. Levi F, Lucchini F, Negri E, La Vecchia C. Continuing declines in cancer mortality in the European Union. Ann Oncol. 2008;18:593-595.

7. Szynglarewicz B, Matkowski R, Kasprzak P, et al. The effectiveness of population-based breast cancer screening programme. Pol Merkur Lekarski. 2009;26:117-120.

8. Matkowski R, Szynglarewicz B. First report of introducing population-based breast cancer screening in Poland: Experience of the 3-million population region of Lower Silesia. Cancer Epidemiol. 2011;35:e111-115.

9. Perry N, Broeders M, de Wolf C, Tornberg S, Holand R, von Karsa L. European guidelines for quality assurance in breast cancer screening and diagnosis. Fourth edition - summary document. Ann Oncol. 2008;19:614-622.

10. De Koning HJ. Breast cancer screening: Cost-effective in practice? Eur J Radiol. 2000;33: 32-37.

11. Szynglarewicz B, Matkowski R. Low cost of cancer detection in the first year of mammographic screening in Poland. Breast. 2011;20:585.

12. van Ineveld BM, van Oortmarssen GJ, de Koning $H J$, Boer R, van der Maas PJ. How cost-effective is breast cancer screening in different EC countries? Eur J Cancer. 1993;29A:1663-1668.

13. Spagnolo G, Zappa M, Paci E, Giorgi D, Rosselli del Turco M. Evaluation of the costs of mammographic screening program in the city of Florence. Epidemiol Prev. 1995;19:330-337.

14. Plans $P$, Casademont L, Salleras L. Cost-effectiveness of breast cancer screening in Spain. Int J Technol Assess Health Care. 1996;12: 146-150.

15. Burnside E, Belkora J, Esserman L. The impact of alternative practices on the cost and quality of mammographic screening in the United States. Clin Breast Cancer. 2001;2:145-152.

16. Lindfors KK, Rosenquist CJ. Needle core biopsy guided with mammography: A study of cost-effectiveness. Radiology. 1994;190:217-222.

17. Liberman L, Fahs MC, Dershaw DD, et al. Impact of stereotaxic core biopsy on cost of diagnosis. Radiology. 1995;19:633-637.

18. Rubin E, Mennemeyer ST, Desmond RA, et al. Reducing the cost of diagnosis of breast carcinoma: impact of ultrasound and imagingguided biopsies on a clinical breast practice. Cancer. 2001;91:324-332.

19. Szynglarewicz B, Matkowski R, Kasprzak P, et al. Diagnostic service effectiveness during the first year of breast cancer screening in the region of Lower Silesia. Adv Clin Exp Med. 2008;17:661-666. 